Incidental acquisition of receptive versus productive knowledge of adjective-noun order in the first exposure through input-based tasks: A case of Iranian young learners of English

Rostamzadeh, Maryam $\bowtie$

English Department, University of Isfahan, Iran (rostamzade_maryam@yahoo.com)

Youhanaee, Manijeh

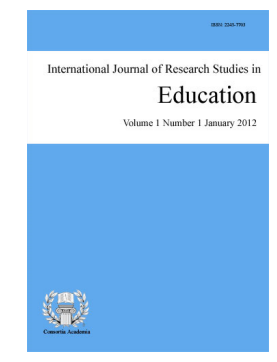

ISSN: 2243-7703 Online ISSN: 2243-7711

OPEN ACCESS

English Department, University of Isfahan, Iran (Youhanaee_m@hotmail.com)

Barati, Hossein

English Department, University of Isfahan, Iran (h.barati@gmail.com)

Received: 9 October 2014

Revised: 15 November 2014

Available Online: 1 December 2014 DOI: 10.5861 /ijrse.2014.978

Accepted: 28 November 2014

\title{
Abstract
}

Being a first exposure one, the current study aimed at answering Gullberg et al.'s (2010) call for studying the relationship between the earliest stages of acquisition in reception and production in order to elucidate how the two modes of language use may interact in the early stages of acquisition. As such, this study was an attempt to compare the effect of first exposure to $\mathrm{L} 2$ through input-based tasks on the receptive and productive acquisition of adjective-noun order. The participants of the study were 20 female Persian-speaking young EFL learners aging eight to ten with no prior experience of EFL learning and thus no knowledge of English. An input-based task, in the form of a listen-and-do task, was performed with plenty examples of adjective-noun order, then assessment tasks of comprehension and production of the target grammatical feature were administered to the participants. Unlike the fact that English and Persian employ different word orders for the target feature, L1 effect did not impede the subjects' acquisition. The reason for this success can be traced back either to the age of participants and on the other hand to the way in which the input-based task facilitated the acquisition. Turning to the relationship between receptive and productive knowledge, results revealed that first exposure learners had a significantly better gain on production of this feature than its comprehension thus supporting more recent views concerning the possibility of the primacy of language production over language comprehension.

Keywords: input-based task; listen-and-do task; incidental learning; young EFL learners; receptive knowledge; productive knowledge 


\section{Incidental acquisition of receptive versus productive knowledge of adjective-noun order in the first exposure through input-based tasks: A case of Iranian young learners of English}

\section{Introduction}

According to Perdue (1996) 'far too little empirical attention has been paid to the very beginnings of the acquisition process' (p. 138). It is essential to assess language learning mechanism practically at first exposure and after minimal exposure to the new language or in other words to control and minimize the effects of previous linguistic knowledge in order to assess the capacities and limitations of the language learning mechanism (Gullberg et al., 2010). This assumption formed the special issue addressed in the present study about incidental acquisition of L2 grammar in 'first exposure' language learners.

Focusing on young learners, the current study was to investigate the effects of first exposure to L2 through listen-and-do tasks that are designed to introduce the new linguistic concept in the form of some preselected vocabularies and a specific grammatical feature (adjective-noun order). As such, the study intended to address a common criticism of task-based teaching (see, for example, Swan, 2005); stating that it fails to provide learners with new language. The task made use of some commands which required the learners to perform some actions. 'adjective-noun order' was not taught directly but used in the commands to see whether listening to such commands led to its incidental acquisition on the first exposure or not. It is worth mentioning that English and Persian employ different word orders for this grammatical structure.

First exposure studies vary in different aspects: the learning problem, properties of the target language, the setting, the research methodology, disciplinary perspectives and the research goals of the researchers. However, according to Carroll (2013) four characteristics form the common ground of first exposure studies:

$>\quad$ such studies are concerned with unconscious or implicit learning mechanisms and processes;

$>\quad$ they aim at studying how such processes operate on input;

$>\quad$ they need to ensure that when tested on some task participants are not making use of representations of the target language previously stored in long-term memory; and

$>\quad$ they decide to control the totality of stimuli of the target language to which the participants are exposed.

It is important to be able to show that learners can start the process of L2 grammar acquisition at the initial stages of learning even when they do not have sufficient vocabularies and grammar resources to guide further learning. Being a first exposure one, the current study aimed at answering Gullberg et al.'s (2010) call for studying the relationship between the earliest stages of acquisition in reception and production in order to demonstrate how the two modes of language use may interact in the early stages of acquisition.

Regarding these two modes of language acquisition, theories of second language acquisition consider the acquisition of receptive grammar processing as preceding the acquisition of productive grammar acquisition. This traditional view is firstly based on the frequently observed primacy of receptive language skills over productive language skills, and secondly on the assumption that a language feature needs to be comprehended before being acquired for production. However, empirical studies showing the primacy of language production over language reception have made the traditional approach to primacy of language reception doubtful. Although it has been acknowledged that the most common grammar acquisition studies involve the acquisition of receptive skills before productive skills, some scholars believe that the opposite is also possible. Thus the generalization of the primacy of each of these two acquisition modes seems to be doubtful and one should be cautious about that. However, other scholars have argued that the methodology used in such studies, in which production precedes comprehension, is problematic and consequently they do not accept the primacy of language production over language comprehension. As it can be seen there is enough justification to take a more cautious stance toward the 
relationship between the receptive and productive modes of acquisition. Until empirical studies test this relationship, the assumption that the development of receptive grammar knowledge precedes the development productive grammar knowledge should be considered doubtful. The current study aims at testing such a relationship.

\section{Review of Literature}

\subsection{First exposure}

A first exposure study is the one in which participants have had no prior exposure to the target language. To date, most of the first exposure studies have mostly focused on aspects of word learning. As an example, Carroll and Widjaja (2013) did a study on aspects of word learning on first exposure to a second language and showed that first exposure learners can map meanings to forms in one limited domain, namely number. They examined the ability of English speakers to learn number-marking in Indonesian which is a language with quite different properties. Indonesian can refer to single and multiple objects with bare nouns, a plural that consists of reduplication, and a numeral classifier construction. Several theories of second language acquisition claim that morphological or syntactic structure will not be learnable at the initial stage of learning, predicting that learners will use only the bare nouns and will use them to express the singular and the plural. Carroll and Widjaja (2013) showed that learners learned all three constructions and retained all three over a two week period. Thus, first exposure learners could learn morpho-syntactic structure on the basis of a limited input. In addition, they could encode and differentiate the meanings of the different constructions.

The current study, drawing on young learners' performance on adjective-noun order comprehension and production, was attempting to investigate initial stages of learning L2 grammar on the first exposure. In this respect, the early learning stages have been compared in terms of receptive and productive knowledge. A special kind of task was used to introduce the target grammatical feature to see whether performing such tasks would lead to incidental acquisition of the target feature after first exposure or not.

\subsection{Limitation on First Exposure Studies}

Most of the first exposure studies done in the area of language learning deal with non-natural and artificial target languages. According to Carroll (2013) one should ask if the use of artificial languages misrepresents the task the L2 learners face. Robinson (2010) draws on studies which investigated Japanese speakers who were also high proficiency English L2 users. The researcher trained them on an artificial grammar and on Samoan. The goal was to show that learning involves both algorithmic and exemplar learning when both artificial and natural languages are being acquired. The findings represented that exemplar-specific knowledge of linear dependencies and abstract knowledge of grammar influenced grammaticality judgments in the case of the artificial grammar. However, high transitional probabilities within a sequence did not influence Samoan L2 learners to correctly accept new items that were grammatical. Robinson concludes that the learning of artificial grammars and natural language grammars are related but involve distinct learning processes. Certainly, more studies that involve first exposure to natural languages under varying conditions of exposure are warranted, as is the continued exploration of the artificial language learning paradigm. This study goes beyond this limitation by exploring first exposure learners of a natural language i.e. English.

\subsection{Listen-and-do Tasks}

Task-based language teaching (TBLT) has mostly been recognized as involving production-based tasks. However, according to Ellis (2009), tasks can also be 'input-based'. An input-based task tries to develop interlanguage development through directing learners' attention to L2 input by reading or listening without requiring them to produce the L2. However, L2 production is not prohibited in an input-based task; learners might decide to react to the input they receive by starting language production (Ellis, 2009). The input-based 
tasks were designed to meet what Ellis (2003) refers to as four essential criteria for a 'task':

$>$ Meaning is primary;

$>\quad$ There is some type of gap (e.g. an information gap);

$>$ Learners are required to use their own linguistic and non-linguistic resources to communicate; and

$>$ There is some outcome other than simply the display of correct language.

Concerning the third entry, learners make use of their own linguistic repertoire together with contextual information to process the input they are exposed to in an input-based task. What is meant by 'process' here involves both comprehending the meaning of the input, and attending to linguistic form (i.e. noticing) when it is required in order to comprehend.

There are different kinds of input-based tasks. The focus of this study was on 'comprehension-based input task'. These tasks expose learners to input and elicit some kind of response to show that processing has happened successfully. That is to say that the outcome of the task can only be achieved if the learners are successful in input comprehension. A comprehension-based task often takes the form of a listen-and-do task; a one-way information gap task that requires subjects to listen to descriptions or commands and then perform some actions (e.g. a physical action or pointing to a picture) to represent that they have understood the commands (Shinani, 2012).

One of the advantages of the listen-and-do tasks (e.g. Ellis et al., 1999; Loschky, 1994) is that they are useful for beginner learners since they provide input which is adjusted to the learners' level in order to make it comprehensible without requiring any production. Ellis (2009), using Prabhu's (1987) work, suggests that a task-based language teaching course for beginners should necessarily be based on input-based tasks since the learners do not have sufficient linguistic resources to engage in meaning-focused language production.

Studies of listen-and-do tasks have shown that they can lead to the successful acquisition of the target features. Shintani (2012) has investigated the use of input-based tasks with young beginner Japanese learners of English as a second language by examining both acquisition and the interactions that resulted from performing the tasks. The participants were 15 learners, aged six, with no experience of second language (L2) learning. The target features were 36 vocabulary items and plural $-s$. The input-based instruction consisted of three listen-and-do tasks, which were repeated nine times over a five-week period. The input-based group improved significantly in their receptive knowledge of plural $-s$ over time but only two learners developed productive knowledge of plural $-s$.

Shintani (2012) suggested that most learners have no difficulty in grasping the rule for English plural marking but they have enormous difficulty in internalizing this rule and producing it correctly. Due to the effectiveness of such tasks, they have been used in this study to see whether they lead to initial stages of incidental grammar acquisition on the first exposure. The word incidental has been used to mean 'learning something without the intention to learn it' or 'learning one thing while intending to learn another'; for example, unintentionally picking up vocabulary, patterns, or spelling through interaction, communicative activities, or reading for content, pleasure. This can be contrasted with intentional learning, for example, learning by following a deliberate program of study to enhance vocabulary or grammar in controlled experiments' (Richards \& Schmidt, 2002, p. 252).

\subsection{Receptive versus productive knowledge}

According to Richards and Schmidt (2002, p. 9) receptive knowledge is 'the ability of a person to understand the speech and writing of other people, also known as passive knowledge' and the productive knowledge is 'the ability of a person to actively produce their own speech and writing, also known as active knowledge'. Taking these definitions into consideration, the receptive and productive knowledge of adjective-noun order have been compared in the current study to see whether first exposure learners can perform better on comprehension or production. 
Incidental acquisition of receptive versus productive knowledge of adjective-noun order

Generally with regard to L1 and L2 acquisition, scholars note that it has been thought for a long time that comprehension always precedes production, because 'before learners start a new task they need to understand what they are doing' (Tasseva-Kurktchieva, 2008, p. 242). Furthermore, as Keenan and MacWhinney (1987) observed 'comprehension is viewed as the primary source of learning to produce language' (p. 149). In Second Language Acquisition (SLA) research dealing with the acquisition of grammar, Krashen argued that 'comprehensible input' is sufficient for language acquisition to take place (e.g. Krashen, 1981; 1985). However scholars now agree that in order for learning to take place from input, input alone is not sufficient but rather have to be combined with output. Furthermore, scholars now also note the difference between comprehension and acquisition. Since comprehension is solely the 'processing of language to get the message' (Cook, 1996, as cited in Gass \& Selinker, 2008, p. 376), it 'will not necessarily lead to grammar formation' (Gass \& Selinker, 2008, p. 486). Instead, in order for language acquisition to take place, learners should process input in a way that they 'break the code'. In other words, they should have an analytic understanding of the input in order for input to turn into intake. Afterwards, this intake can be used to acquire the grammar of the language. In short 'semantic comprehension is a prerequisite to syntactic comprehension and syntactic comprehension is a prerequisite to acquisition' (Gass \& Selinker, 2008, p. 375).

All taken together, although learning a new language involves the development of both receptive and productive language skills, researchers have focused rarely on the development of receptive skills as such. Rather, comprehension -especially analytic comprehension- is viewed as a requirement for acquisition to take place. Thus it can be said that before L2 learners (or L1 learners) are able to produce a grammatical feature, they have acquired a receptive knowledge of that.

When the target language grammar has been acquired, traditional views on grammar see this grammar as a 'direction-insensitive system of rules' (Hendriks, 2007, p. 240). In other words, people have one mental grammar which gives them the ability to both comprehend and produce language. The balance between a person's comprehension and production competences supports this view, as can be observed in fully acquired L1s particularly: when someone is able to produce a grammatical structure, he/she is able to comprehend it too, and vice versa (Hendriks, de Hoop, \& Lamers, 2005; Hendriks \& Koster, 2010).

Different language theories have different views on the importance of input in L2 acquisition, and on the particular ways in which learners use this input to acquire language. Universal Grammar, for example, views input as an activator which activates humans' innate mental grammar (Ellis, 2008). In other cognitive theories of language acquisition, the existence of an innate grammatical system has been rejected and learners are said to use general learning mechanisms to acquire the target language grammar (ibid.). Moreover, assumptions with regard to the form which mental grammars have differ in different theories. Despite these differences, SLA researchers, supporting any of the theories on language acquisition, seem to agree, both on the idea that language comprehension serves acquisition and thus precedes production, and on the position that when the target language is acquired, knowledge of the language, or mental grammar system, is used for both comprehension and production.

This explains why language reception has not been studied much. Although it may be true, that the product of receptive language knowledge is much less easily accessible, it can be also added to this that there was also no real need to study the acquisition of receptive language skills. Based on the observation that learners understand a new language before they produce it and on the assumption that reception serves acquisition, it is reasonable that whatever observations are made based on productive language data will be also applicable to language reception.

Recently, however, the traditional views on the relationship between receptive and productive second language acquisition have been challenged. Although, as de Hoop and Kramer (2006) write with regard to L1 acquisition, ' in general young learners' abilities in comprehension precedes their abilities in production' (p. 120), several cases have been observed where production surpasses comprehension. These cases concern not just L1 acquisition (e.g. Hurewitz, Brown-Schmidt, Thorpe, Gleitman, \& Trueswell, 2000; Spenader, Smits, \& Hendriks, 
Rostamzadeh, M., Youhanaee, M., \& Barati, H.

2009), but also L2 acquisition (Unsworth, 2007; Tasseva-Kurktchieva, 2008). Furthermore, they deal with both the acquisition of grammar and the acquisition of lexical items (Bates, Dale, \& Thal, 1995).

Tasseva-Kurktchieva, (2008) and Unsworth, (2007) argue that the results of studies which have demonstrated the dominance of productive knowledge over receptive knowledge might not be valid due to methodological errors. Bates et al. (1995), as an instance, explain that in studies where the productive knowledge of grammatical items preceded the receptive knowledge, the results were either due to the 'complexity of tasks demands that obscures the child's actual knowledge of grammatical structures' (p. 8), or to the fact that the learners produced memorized and unanalyzed chunks of language which contained the grammatical items being investigated, thus giving the impression that they had acquired these grammatical features while really they had not.

Despite these criticisms, other researchers have taken this evidence serious. In trying to explain the primacy of language reception over language production, some scholars have mentioned computational limitations or processing-problems encountered by learners during the comprehension process (e.g. Hurewitz et al., 2000; Unsworth, 2007). Still others appeal the absence of specific pragmatic knowledge required for receptive processing which is not required for productive processing -though this view appears to be debated (Hendriks \& Coster, 2010).

In addition, some scholars regard these production/comprehension irregularities as 'a result of the grammar'. While the possibility that learners have different grammars for comprehension and production is generally rejected (e.g. Hendriks \& Koster, 2010; Tasseva-Kurktchieva, 2008), the traditional direction-insensitive view on grammar is questioned by some scholars (e.g. Hendriks, 2007). Notably Optimality Theory (OT), which posits a direction-sensitive grammar, accounts for asymmetries between production and comprehension. In Hendriks' (2007) words, 'in Optimality Theory (OT), production and comprehension are modeled as different directions of use of the same grammar' (p. 2). It is possible, therefore, that a grammar feature can be mastered in one direction but not in another. Thus, OT accounts for the usually found primacy of language reception over language production as well as for the less usual primacy of language production over language reception.

To summarize then, concerning the acquisition of receptive and productive skills, the above discussion has shown that the relationship between the acquisition of receptive grammar knowledge and the acquisition of productive language skills is far from straightforward. In traditional views, receptive knowledge is seen as preceding productive skills in the acquisition of L2 grammar - and other aspects of language for that matter because it is believed that in order for acquisition to take place learners must first process input at an analytic level. On the basis of this analytic processing, it is posited, input can turn into intake, which in turn is used for acquisition. Furthermore, SLA researchers usually regard grammar as a uni-directional system: once the target language grammar system has been acquired, it is used both for comprehending and producing language.

On the basis of some recent empirical evidence which shows a primacy of language production over language reception, however, scholars have challenged these traditional views. Although to date the traditional views on language reception still dominate SLA, and scholars have even challenged the validity of studies claiming to contradict this view, it may be clear that more research will be needed to either reject or confirm the more recent theories. As it was mentioned above, the different views existing in literature regarding the primacy of either of language comprehension or production has led the researcher to find about this aspect by examining he receptive and productive acquisition of a target feature which may be subject to L1 effect. So as to find out whether the traditional views on language reception in which studies of productive language acquisition can also be applied to language reception will be supported or the recent challenges that have been posed to the traditional views.

\subsection{L1 Effect}

It is also worth mentioning that English and Persian employ quite different structures for adjective noun order. In English adjective precedes the noun, while in Persian adjective follows the noun. The following example clarifies the point: 

a) Ketab-e- zærd
b) book yellow
c) yellow book

Regarding the fact this feature varies among Persian and English structures, Persian learners of English may face difficulties (raised by L1 effect) acquiring these two features.

To sum up, the current study attempts to fill gaps in the research into first exposure studies by comparing the comprehension and production of adjective-noun order. It investigates whether listen-and-do tasks can create rich opportunities for language learning by young children who are learning target language for the first time. The research question addressed in this study is as follows:

$>\quad$ Is there any significant difference between the receptive and productive knowledge of adjective-noun order on the first exposure to L2 input through listen-and-do tasks?

\section{Methodology}

\subsection{Design}

This study employed a pre-experimental one shot case study design, in which a single intact group was measured at a single point in time after some treatment that was presumed to have caused change. The target group was compared to general expectations. No control or comparison group was employed, neither were any pretests administered since the participants were complete zero beginner learners who had no experience of studying English and thus no knowledge of English. According to Hatch and Farhady (1981), 'In this design, there is no control group and students are given some experimental instruction or treatment for a given period of time. At the end of the period of time, the students receive some sort of test on the treatment' (p. 19-20).

\subsection{Participants}

The participants of this study were female students, aged 8 to 10 , with no prior experience of foreign language learning. They had exposure to English only in this research project. They were selected through purposive sampling based on the criteria of being complete zero beginners. To this end their parents were orally asked about whether their children had studied English elsewhere or not. The parents of the children and the head of the language institute, in which the treatment was administered, were informed in detail about the project and their consent was obtained.

\subsection{Instruments}

The assessment tasks used in the present study to assess early knowledge of the receptive and productive knowledge of adjective-noun order after first exposure to L2 input are provided in this section. They include 'Picture-matching comprehension task for adjective-noun order' and 'Picture description production task for adjective-noun order'. These researcher-made assessment tasks, after receiving expert judgment, were piloted with a group of first exposure learners at the same age who were not the target participants. In this pilot study, the issues regarding the administration, time allocation, clarity of test rubric, appropriacy of the language of input, and other issues were surveyed and necessary changes were made to the assessment tasks. The researcher used the results of the piloting phase to measure reliability of the assessment tasks. To this end Cronbach's alpha was applied. Cronbach's alpha for the "picture-matching comprehension task for adjective-noun order" was 0.917 which is very good and shows that the results are highly reliable. The Cronbach's alpha for the "picture-description production task for adjective-noun order" was 0.625 which is good.

Picture-matching comprehension task for adjective-noun order - The aim of this task was to assess the receptive knowledge of adjective-noun order. It contained 18 sets, each set consisted of a picture representing a 
concept related to one of the adjectives of size or color. Students listened to four audio recorded phrases in each set as they were looking at the picture and they had to circle $(\sqrt{ })$ if the phrase they heard matched the picture or (X) if it didn't. Table 1 is an example of two of the sets of this task (the first and the fourth set). As it can be seen, the first concept represented is a 'big apple', students heard phrase $\boldsymbol{A}$ as 'big apple', phrase B 'apple big', phrase C 'small apple' and phrase D 'apple small'. The task sheets were provided for students in color print in order to clearly show the concept of color. They had five seconds to answer each item. Care was taken to ensure that the participants could not see other students' test papers during the task.

\section{Table 1}

Picture-matching comprehension task for adjective-noun order

\begin{tabular}{lccccccccc}
\hline & Audio-recorded phrases & A: big apple & B: apple big & C: small apple & D: apple small \\
\hline $\begin{array}{l}\text { Concept: } \\
\text { Big apple }\end{array}$ & Audio-recorded phrases & A: rabbit big & B: rabbit small & C: big rabbit & D: small rabbit \\
\hline $\begin{array}{l}\text { Concept: } \\
\begin{array}{l}\text { Small } \\
\text { rabbit }\end{array}\end{array}$ & $\mathrm{X}$ & $\sqrt{ }$ & $\mathrm{X}$ & $\sqrt{ }$ & $\mathrm{X}$ & $\sqrt{ }$ & $\mathrm{X}$ & \\
\hline
\end{tabular}

Picture description production task for adjective-noun order - The aim of this task was to assess the productive knowledge of adjective-noun order. This task included 9 items. Each item was a flashcard with a picture the description of which required using an adjective-noun order. For example a picture of a 'yellow book' was presented and they had to say the phrase. The test was administered to participants individually by the researcher. Ample time was given to the participants to say what they saw. If a participant was unable to provide an answer, the researcher would say the phrase in Persian and asked the learners to do the same in English.

\subsection{Procedure}

The data of this study was collected through instructional treatment and assessment tasks during two 90-minute sessions. Since the participants were zero beginner learners, the first session was dedicated to teach the 16 vocabulary items necessary for the main treatment in the following session. Since the vocabulary items were not the target of this study, they were taught directly by the use of flashcards and ample repetitions. The vocabulary items are shown in Table 2 .

\section{Table 2}

Vocabulary items

\begin{tabular}{ll}
\hline Nouns & lion, tiger, rabbit, fox, apple, book, cup, peach, orange, zoo, market \\
\hline Adjectives & Big, small, red, yellow, blue \\
\hline
\end{tabular}

A listen-and-do task, which was adopted from Shintani's task (2011), and then adapted by the researcher, was used in the second session. The task involved the participants listening to teacher's commands and responding to them.

The task is called 'Let's go to the zoo and the market' which required the learners to listen to the teacher's commands and took the picture cards corresponding to the target item(s) to the zoo or the market. The participants were informed that the purpose of this task was to help the zoo or the market by finding the right cards and placing them in the zoo or the market. They listened to an instruction, found the cards that matched the instruction, and then when they were told to do so by the teacher, they took the cards they had chosen to the zoo or market. Sample instructions were 'Take a big lion to the zoo'; 'Take a blue book to the market'. Instructions contained the target grammatical feature of the study (i.e. adjective-noun order). 
During the second session, the listen and do task was performed. The aim was to see whether learners could start acquiring adjective-noun order incidentally as a result of performing listen and do tasks on the first exposure. Performing the task took the form of a game lasting for an hour. At the end of this session the comprehension and production assessment tasks of adjective-noun order were administered. The assessment phase took 30 minutes.

\section{Results}

In order to find out on which assessment tasks of adjective-noun order students had a better gain, the participants' performance mean percentages were visually presented and contrasted in figure 1. On a closer inspection of the mean scores given in the figure, one can clearly see that the subjects gained a higher mean score on adjective-noun order production than adjective-noun order comprehension (adjective-noun order production=83.89 $>$ adjective-noun order comprehension=70.83).

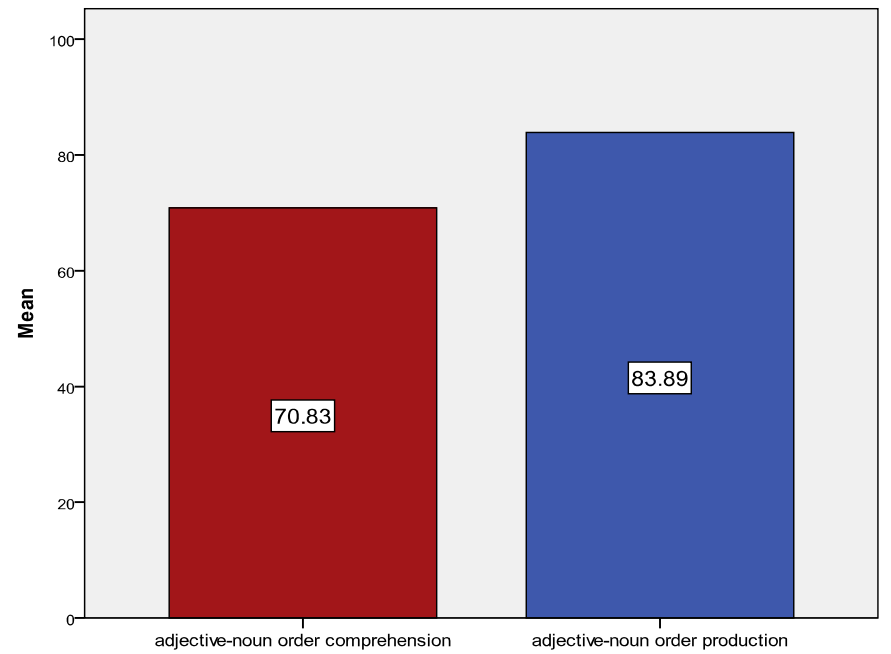

Figure 1. The comparison of adjective-noun order comprehension and production

However, the researcher had to go further to find out whether or not the observed difference was significant. Therefore, the results of the t-test were taken into account. A paired sample t- test was performed on the students' scores derived from 'picture-matching comprehension task for adjective-noun order' and 'picture description production task for adjective-noun order'. It was found that $\mathrm{t}=-2.454$, the degree of freedom is 19 and the $\mathrm{p}$ value of $0.024 \leq 0.05$ (Table 3). So the null hypothesis, stating the means of the two tasks are equal, is rejected. Thus, it can be concluded that there is a relatively significant difference between the group's performance on the two above-mentioned assessment tasks.

\section{Table 3}

Adjective-noun order paired sample t-test

\begin{tabular}{lcccccc}
\hline & \multicolumn{3}{c}{ Paired Differences } & & \\
\cline { 2 - 6 } & Mean & $\begin{array}{c}\text { Std. } \\
\text { Deviation }\end{array}$ & $\begin{array}{c}\text { Std. Error } \\
\text { Mean }\end{array}$ & t & df & $\begin{array}{c}\text { Sig. } \\
\text { (2-tailed) }\end{array}$ \\
\hline $\begin{array}{l}\text { Adjective-noun order } \\
\text { comprehension } \\
\begin{array}{l}\text { and } \\
\text { adjective-noun order } \\
\text { production }\end{array}\end{array}$ & -13.056 & 23.795 & 5.321 & -2.454 & 19 & .024 \\
\hline
\end{tabular}

\section{Discussion and conclusion}

As can be seen from the mean scores, learners were not absolutely constrained by L1 properties in their 
analysis of L2 input. In other words, unlike the fact that English and Persian employ different word orders, participants were successful at initial stages of adjective-noun order acquisition after first exposure. Carrol and Widjaja (2013) obtained the same result showing that L1 effect did not impede L2 learning for first exposure learners. This finding can be used as an evidence for McKay's (2006) claims stating that even in the very early stages of language learning, despite having limited language ability, learners are able to make an initial move towards language use, both in the receptive and productive modes. He further claims that young learners are able to make rapid and sure advances in their ability to use language too if they have the appropriate language environment in which to grow. This can be used as an answer to the criticism of task-based teaching (see, for example, Swan, 2005); namely, that it fails to provide learners with new language. The reason for this success can be traced back to the age of participants, being young learners, and on the other hand to the way in which the input-based task facilitated the acquisition.

The participants had a relatively more significant gain at production of this grammatical feature than its comprehension $(t=-2.454, p=0.024)$. Contrary to the fact that production puts a heavier cognitive load on language learners than comprehension, here it is seen that participants have been more successful at production. This way the more recent empirical evidence which shows a primacy of language production over language reception is supported and the traditional approach to primacy of language reception seems to be doubtful and needs further investigation. Although traditional views acknowledge that the most common grammar acquisition studies show the acquisition of receptive skills before productive skills, some scholars believe that the opposite is also possible and the same case was observed in the current study.

However this finding is not in line with Optimality Theory which accounts for the usually found primacy of language reception over language production as well as for the less usual primacy of language production over language reception. It should be taken into consideration that such a result may be to some extent because of the nature of the assessment tasks administered for this feature; 'Picture description production task for adjective-noun order' was easier in format than 'Picture-matching comprehension task for adjective-noun order'. This can be said to be one of the limitations of the current study. This is in line with what was found from literature showing several cases which have been proved where production precedes comprehension (exactly what was observed in this part of the results of the current study), (e.g. Hurewitz, Brown-Schmidt, Thorpe, Gleitman \& Trueswell, 2000; Spenader, Smits, \& Hendriks, 2009) and L2 acquisition (Unsworth, 2007; Tasseva-Kurktchieva, 2008). Furthermore, they are dealing with both the acquisition of grammar and the acquisition of lexical items (Bates, Dale, \& Thal, 1995). Tasseva-Kurktchieva, (2008) and Unsworth, (2007) argue that the results of studies which have shown the dominance of productive acquisition over receptive acquisition might not be valid due to methodological errors. According to Bates et al. (1995), two reasons can be provided for such results; firstly 'the complexity of tasks demands that obscures the child's actual knowledge of grammatical structures' (p. 8), or secondly to the fact that the children produced unanalyzed and memorized chunks of language which contained the grammatical items under investigation, thus giving the impression that they had acquired these grammatical features while really they had not.

The experiment presented here is the starting point for a range of further investigations. This study was limited in terms of the number of participants. Replicating the same study with more participants along with a control group would make it more feasible to generalize the findings. Another suggestion is to replicate the current study with a group of first exposure adult language learners to see if age would alter the obtained results. Since the question of possible maturational constraints on L2 acquisition-both in production and in comprehension-remains a key issue for language acquisition studies. Thus different results might be obtained doing the same study on first exposure adult learners and/or with teaching methods rather than task-based language teaching. A comparison can also be made in how age interacts with the linguistic domain under study. As an example, it is said that adults are faster, or at least not slower, than children in initial stages of acquisition for morphosyntax (e.g. Slavoff \& Johnson, 1995) or phonology (e.g., Loewenthal \& Bull, 1984).

In contrast, in the lexical domain children are sometimes thought to be both faster and better than adults 
Incidental acquisition of receptive versus productive knowledge of adjective-noun order

(Carey \& Bartlett, 1978). It is hoped that some contribution is made to the studies done in this area of research within which there is a dearth of investigation and information especially in Iranian context. Besides, it is believed that this study covered a narrow scope of the current issue, and other researchers are recommended to carry out related studies to add to the body of literature in this regard. Again, most studies of this type have not examined the very initial stages (Roberts et al., 2012). This study aimed to probe this issue by comparing comprehension and production of adjective-noun order in 8-to-10-year-olds. Other researchers are suggested to examine the relationship between receptive and productive knowledge more, to see which view will be supported, either the traditional ones emphasizing the primacy of receptive knowledge or the more recent empirical one showing the primacy of production.

In conclusion, the present study suggests that at the earliest stages of L2 acquisition and in the absence of preexisting knowledge to bootstrap and boost learning, the child learning mechanism can deal efficiently with very little input in receptive and productive modes. This mechanism appeared to be a bit more powerful than typically assumed in the L2 acquisition literature. The input-based tasks provided a powerful learning atmosphere allowing the child learning mechanism to extract considerable amounts of linguistic information incidentally and even produce it more successfully than comprehension. Although above-chance performance on experimental tasks is a long distance and something different from successful L2 acquisition, it is believed that some progress has been made toward answering Clive Perdue's call for more empirical research on the earliest stages of acquisition, which is crucial to overall understanding of L2 acquisition.

As a final remark, it is worth mentioning that the researchers dealing with controlled input studies with firs exposure learners are trying to show that these learners can demonstrate signs of linguistic distinctions rapidly, given the input whose characteristics can be studied independently. Such results could not be obtained from longitudinal corpus studies where there is no control over input and learners have weeks or months of exposure before they are first recorded.

\section{References}

Bates, E., Dale, P.S., \& Thal, D. (1995). Individual differences and their implications for theories of language development. In P. Fletcher \& B. MacWhinney, (Eds.), The handbook of child language (pp. 96-151). Oxford, England: Blackwell Publishers.

Carey, S., \& Bartlett, E. (1978). Acquiring a single new word. Papers and Reports on Child Language Development, 15, 17-29.

Carroll, S. E. (2013). Introduction to the special issue: Aspects of word learning on first exposure to a second language. Second Language Research, 29(2), 131-144. http://dx.doi.org/10.1177/0267658312463375

Carroll, S. E., \& Widjaja, E. (2013). Learning exponents of number on first exposure to an L2.Second Language Research, 29(2), 201-229. http://dx.doi.org/10.1177/0267658312473471

Cook, V. (1996). Second language learning and language teaching. London: Arnold.

De Hoop, H., \& Krämer, I. (2005). Children's optimal interpretations of indefinite subjects and objects. Language Acquisition, 13, 103-123. http://dx.doi.org/10.1207/s15327817la1302_4

Ellis, N. C. (2003). Constructions, chunking, and connectionism: The emergence of second language structure. In C. J. Doughty, \& M. H. Long, (eds.), The handbook of second language acquisition (pp. 63-103). Oxford: Blackwell. http://dx.doi.org/10.1002/9780470756492.ch4

Ellis, R. (2008). The study of second language acquisition (2nd ed.). Oxford: Oxford University Press.

Ellis, R. (2009). Task-based language teaching: Sorting out the misunderstanding. International Journal of Applied Linguistics, 19, 221-246. http://dx.doi.org/10.1111/j.1473-4192.2009.00231.x

Ellis, R., \& He, X. (1999).The roles of modified input and output in the incidental acquisition of word meanings. Studies in Second Language Acquisition, 21, 285-301. http://dx.doi.org/10.1017/S0272263199002077

Gass, S., \& Selinker, L. (2008). Second language acquisition: An introductory course (3rd ed.). New York: Routledge.

Gullberg, M., Roberts, L., Dimroth, C., Veroude, K., \& Indefrey, P. (2010). Adult language learning after minimal 
Rostamzadeh, M., Youhanaee, M., \& Barati, H.

exposure to an unknown natural language. Language Learning, 60(2), 5-24. http://dx.doi.org/10.1111/j.1467-9922.2010.00598.x

Hatch, E. M., \& Farhady, H. (1982). Research design and statistics for applied linguistics. Rowley, Mass: Newbury House.

Hendriks, P. (2007). A unified explanation for production/comprehension asymmetries. In A. Gavarró Algueró, \& M. J. Freitas, (Eds.), Proceedings of GALA 2007(pp. 240-251). Newcastle upon Tyne, UK: Cambridge Scholars Publishing.

Hendriks, P., \& Koster, C. (2010). Production/comprehension asymmetries in language acquisition. Lingua, 120(8), 1887-1897. http://dx.doi.org/10.1016/j.lingua.2010.02.002

Hendriks, P., de Hoop, H., \& Lamers, M. (2005). Asymmetries in language use reveal asymmetries in the grammar. In P. Dekker, \& M. Franke, (Eds.), Proceedings of the 15th Amsterdam Colloquium ILLC (pp. 113-118). Amsterdam.

Hurewitz, F., Brown-Schmidt, S., Thorpe, K., Gleitman, L. R., \& Trueswell, J. C. (2000). One frog, two frog, red frog, blue frog: Factors affecting children's syntactic choices in production and comprehension. Journal of Psycholinguistic Research 29(6), 597-626. http://dx.doi.org/10.1023/A:1026468209238

Keenan, J. M., \& MacWhinney, B. (1987). Understanding the relationship between comprehension and production. In H. W. Dechert, \& M. Raupach, (Eds.), Psycholinguistic models of production (pp. 149-155). Norwood, NJ: Ablex Publishing Co.

Krashen, S. (1981). Second language acquisition and second language learning. Oxford:Pergamon.

Krashen, S. (1985). The input hypothesis: Issues and implications. London, New York: Longman.

Loewenthal, K., \& Bull, D. (1984). Imitation of foreign sounds: what is the effect of age? Language and Speech, 27, 95-97.

Loschky, L. (1994). Comprehensible input and second language acquisition: What is the relationship? Studies in Second Language Acquisition, 16, 303-324. http://dx.doi.org/10.1017/S0272263100013103

McKay, P. (2006). Assessing young language learners, Cambridge, Cambridge University Press.

Perdue, C. (1996). Pre-basic varieties: The first stages of second language acquisition. Toegepaste taalwetenschap in artikelen. 2, 135-149. http://dx.doi.org/10.1075/ttwia.55.11per

Prabhu, N. S. (1987). Second language pedagogy. Oxford: Oxford University Press.

Richards, J., \& Schmidt, R. (2002). Longman dictionary of language teaching and applied linguistics. Malaysia: Pearson Education.

Roberts, L., Dimroth, C., \& Gullberg, M. (2012). What word-level knowledge can adult learners acquire after minimal exposure to a new language? International Review of Applied Linguistics, 50, 239-276.

Robinson, P. (2010). Implicit artificial grammar and incidental natural second language learning: How comparable are they? Language Learning, 60, 245-63. http://dx.doi.org/10.1111/j.1467-9922.2010.00608.x

Shintani, N. (2011). A comparative study of the effects of input-based and production-based instruction on vocabulary acquisition by young EFL learners. Language Teaching Research, 15, 137-58. http://dx.doi.org/10.1177/1362168810388692

Shintani, N. (2012). Input-based tasks and the acquisition of vocabulary and grammar: A process-product study. Language Teaching Research, 16(2), 253-279. http://dx.doi.org/10.1177/1362168811431378

Slavoff, G. R., \& Johnson, J. S. (1995). The effects of age on the rate of learning a second language. Studies in Second Language Acquisition, 17, 1-16. http://dx.doi.org/10.1017/S0272263100013723

Spenader, J., Smits, E. J., \& Hendriks, P. (2009). Coherent discourse solves the Pronoun Interpretation Problem. Journal of Child Language, 36, 23-52. http://dx.doi.org/10.1017/S0305000908008854

Tasseva-Kurktchieva, M. (2008). What about grammar? Comprehension and production at the initial stage of L2 acquisition. In R. Slabakova et al. (Eds.), Proceedings of the 9th Generative Approaches to Second Language Acquisition Conference (pp. 242-250). Somerville, MA: Cascadilla Proceedings Project.

Unsworth, S. (2007). L1 and L2 acquisition between sentence and discourse: Comparing production and comprehension in child Dutch. Lingua, 117, 1930-1958. http://dx.doi.org/10.1016/j.lingua.2006.11.009 